\title{
COMPLEMENTARY AND ALTERNATIVE THERAPY FOR PAIN AND ANXIETY IN CARDIOVASCULAR DISEASE: A LITERATURE REVIEW
}

\author{
${ }^{1}$ Indah Sri Wahyuningsih, ${ }^{2}$ Moses Glorino Rumambo Pandin \\ ${ }^{1}$ Student of Doctoral Program in Nursing, Faculty of Nursing, Airlangga University \\ ${ }^{2}$ Associate Professor, Faculty of Cultural Sciences, Airlangga University \\ Email: indah.sri.wahyuningsih-2020@fkp.unair.ac.id
}

\begin{abstract}
Cardiovascular disease is the first leading cause of death in the world. Patients with cardiovascular disease may experience various problems, including physiological and psychological problems. Apart from pharmacological therapy, complementary therapy is necessary as a support to conventional medicine. This review aims to describe complementary and alternative therapies for pain and anxiety in patients with cardiovascular disease. This review utilized data from ProQuest, ScienceDirect, and PubMed with search keywords of "Complementary" AND "Nursing" AND "Pain" AND "Anxiety" AND "Coronary artery disease". Ten articles that met the inclusion criteria were analyzed. The results show that nursing actions increasingly develop along with the patient needs. One form of holistic nursing action is complementary and alternative therapy (CAT) that consists of three categories: body-based methods, mind therapies, and sensory therapies. CAT has positive impacts on patients with heart disease. It can reduce anxiety and pain, lower blood pressure, and improve the quality of life. This review also shows that CAT has a positive impact on the recovery of patients with heart disease. Proper therapeutic management should be implemented to reduce the risks of physiological and psychological problems in patients.
\end{abstract}

Keywords: Anxiety, complementary therapies, coronary artery disease, pain

\section{INTRODUCTION}

Cardiovascular disease is the first leading cause of death in the world. The data from WHO show that more than 17 million people worldwide die from heart and blood vessel diseases (1). The Basic Health Research (Riskesdas) also shows that the incidence of heart and blood vessel diseases increases from year to year; 15 out of 1,000 people, or around 2,784,064 people in Indonesia, suffer from heart disease (2). Patients with cardiovascular disease experience both physiological and psychological problems. Nearly $40 \%$ of patients with myocardial disease experience psychological disorders such as depression, anxiety, and stress (3), Furthermore, after heart 
surgery, patients with cardiovascular disease also experience similar problems such as anxiety, depression, pain, and other problems that affect the recovery process (4).

The problems that occur in patients with cardiovascular disease can cause prolonged treatment during the recovery period. The patients often complain of chest pain that decreases pulmonary ventilation and lengthens hospitalization. Anxiety can decrease coronary blood flow and increase sympathetic nerve activity, the workload of the heart, heart rate, and breathing (5). The first intervention that can be provided for these patients is pharmacological therapy. However, this intervention may cause side effects for patients. The provision of non-pharmacological interventions is thus necessary to treat chest pain and anxiety in patients. Also, complementary and alternative therapies are recommended to reduce pain and anxiety in patients with acute myocardial infarction (AMI).

Complementary and alternative therapy (CAT) is an alternative that nurses can provide for patients to manage pain and discomfort. CAT is used as a substitute for traditional medicine. The CAT approaches that can be implemented in patients include deep breathing, yoga, meditation, diet relaxation, and guided imagery therapy (6). These therapies are innovations in providing holistic nursing care that can reduce discomfort in patients with cardiovascular disease. Accordingly, this study aims to identify complementary and alternative therapies applied to patients with cardiovascular disease to reduce pain and anxiety.

\section{METHOD}

This study is a literature review that explores complementary and alternative therapies to reduce pain and anxiety in patients with cardiovascular disease. The articles used in this review were obtained from the electronic databases of ProQuest, Science Direct, and PubMed. The keywords used for searching the articles included "Complementary" AND "Nursing" AND "Pain" AND "Anxiety" AND "Coronary artery disease". Articles that met the following criteria were included: the study population was patients with cardiovascular disease; the intervention was complementary and alternative therapy; the outcome was the decreased pain and anxiety problems; the articles were published from 2019-2021. 


\section{RESULTS}

Table 1. The distribution of CAT in patients with cardiovascular disease

\begin{tabular}{llll}
\hline Authors, Year & Medical diagnosis & $\begin{array}{l}\text { Complementary and } \\
\text { Alternative therapy }\end{array}$ \\
\hline Vasokolaei, & Coronary artery & Hand reflexology and & Hand reflexology and \\
Zohre R et al., disease & acupressure & acupressure have effects \\
2019 & & on reducing anxiety and \\
& & lowering blood pressure.
\end{tabular}

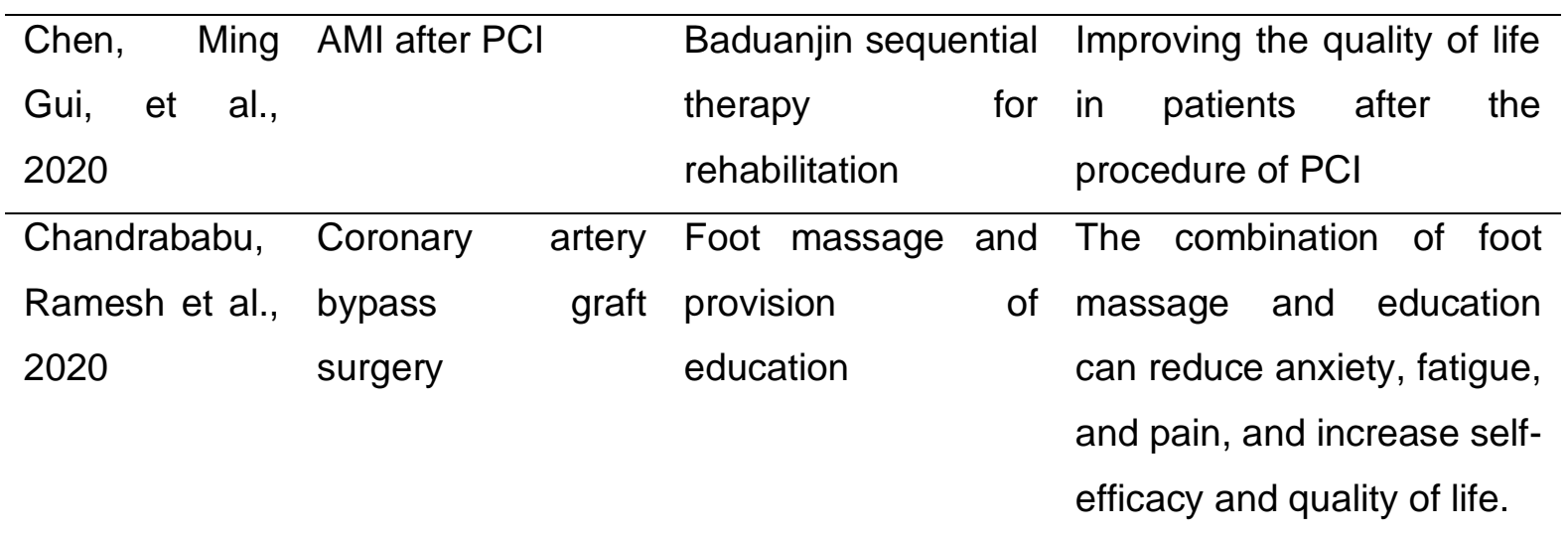

\begin{tabular}{|c|c|c|c|}
\hline $\begin{array}{l}\text { Akbari, } \\
\text { Fatemah et al., } \\
2019\end{array}$ & $\begin{array}{l}\text { Intravenous } \\
\text { catheterization in } \\
\text { cardiac patients }\end{array}$ & $\begin{array}{l}\text { Aromatherapy, } \\
\text { Peppermint essence }\end{array}$ & $\begin{array}{l}\text { Peppermint aromatherapy } \\
\text { can reduce pain and anxiety } \\
\text { in patients before } \\
\text { undergoing catheterization. }\end{array}$ \\
\hline $\begin{array}{l}\text { Chandrababu, } \\
\text { Ramesh et al., } \\
2019\end{array}$ & Cardiac surgery & Pranayama & $\begin{array}{l}\text { The physical practice of } \\
\text { yoga pranayama reduces } \\
\text { anxiety scores in patients } \\
\text { undergoing cardiac surgery. }\end{array}$ \\
\hline $\begin{array}{l}\text { Nijjar, Prabhjot } \\
\text { et al., } 2019\end{array}$ & $\begin{array}{l}\text { Cardiac } \\
\text { rehabilitation }\end{array}$ & $\begin{array}{l}\text { Mindfulness-based } \\
\text { stress reduction } \\
\text { (MBSR) }\end{array}$ & $\begin{array}{l}\text { MBSR can reduce } \\
\text { psychosocial problems in } \\
\text { patients with heart disease } \\
\text { during the recovery period. }\end{array}$ \\
\hline $\begin{array}{l}\text { Amjadian, } \\
\text { Mohidian et al., } \\
2020\end{array}$ & $\begin{array}{l}\text { Coronary artery } \\
\text { bypass surgery }\end{array}$ & $\begin{array}{l}\text { Islamic spiritual } \\
\text { intervention and } \\
\text { breathing techniques }\end{array}$ & $\begin{array}{l}\text { Islamic spiritual intervention } \\
\text { and breathing exercises are } \\
\text { used as rehabilitation } \\
\text { programs for patients with } \\
\text { CABG. }\end{array}$ \\
\hline
\end{tabular}




\begin{tabular}{|c|c|c|c|}
\hline $\begin{array}{l}\text { Rokni, } \\
\text { Fatemah F et } \\
\text { al., } 2019\end{array}$ & Surgery of CABG & $\begin{array}{l}\text { Aromatherapy with } \\
\text { rose essentials }\end{array}$ & $\begin{array}{l}\text { Inhalation of rose essential } \\
\text { aromatherapy can reduce } \\
\text { anxiety. }\end{array}$ \\
\hline $\begin{array}{l}\text { Rambood, } \\
\text { Masoume et } \\
\text { al., } 2020\end{array}$ & $\begin{array}{l}\text { Acute myocardial } \\
\text { infarction }\end{array}$ & $\begin{array}{l}\text { Lemon } \\
\text { aromatherapy }\end{array}$ & $\begin{array}{l}\text { Inhalation of lemon } \\
\text { aromatherapy can lower } \\
\text { systolic blood pressure, } \\
\text { anxiety, pulse, T-waves, } \\
\text { and blood pressure } \\
\text { regulation. }\end{array}$ \\
\hline $\begin{array}{l}\text { Dai Wang et } \\
\text { al., } 2020\end{array}$ & Patients with CABG & Music therapy & $\begin{array}{l}\text { Patients who are given } \\
\text { music therapy have the } \\
\text { decreased pain and anxiety } \\
\text { scores after CABG. }\end{array}$ \\
\hline
\end{tabular}

\section{DISCUSSION}

CAT is a therapy that is used in conjunction with other traditional therapies. The use of CAT is congruent with Florence Nightingale's theory, describing that the practice of holistic nursing may involve the use of heat, massage, music, and touch therapies. This concept is in accordance with CAT components as one form of nursing care (6). Complementary therapy can be given to patients with acute and chronic problems. In this regard, nurses are responsible for providing a holistic approach to control pain and open minds to complementary therapies. Pharmacological treatment to reduce pain in patients is relatively costly and causes side effects, so that patients can choose CAT as a part of their treatment. Nurses play a role in the patients' holistic assessment by comprehensively exploring treatment history and physical examinations. Holistic nursing plans are practiced by discussing with patients ways to achieve the final goal to reduce pain (7). CAT is divided into some categories, namely body-based methods, energy therapies, diet and herbal preparations, mind therapies, sensory therapies, and movement therapies. This literature review shows that there are three main categories of CAT, namely body-based methods, mind therapies, and sensory therapies. The CAT description is provided in detail in the following sections.

\section{Body based Methods}

This literature review shows that CAT, which belongs to the body-based methods, includes hand reflexology, acupressure, and foot massage. Hand reflexology is a type of massage that is well known in general and scientific studies. 
Reflexology points are very simple and easy to practice (8). Hand reflexology and acupressure can be applied to patients admitted to cardiac intensive care (ICCU). Patients who receive hand reflexology and acupressure may benefit from their mental, emotional, or psychological mechanisms. With the touch of the hands and contact with the skin, the body will release the endorphins and produce a feeling of relaxation (9) so that anxiety is reduced and blood pressure returns to normal values. The results of other studies are related to foot massage and education to patients who will undergo CABG surgery. Research showed that patients who received foot massage lowered their scores of anxiety, pain, and fatigue significantly with $p<0.05$. The group receiving the therapy significantly decreased their scores of anxiety, pain, and fatigue. Foot massage therapy has been shown to reduce pain scores in patients with heart surgery (10). Decreased anxiety and pain have a positive impact on increasing the quality of life of patients with cardiovascular disease. Also, pranayama yoga has a positive impact on patients with heart problems after surgery.

Pranayama is a regular yoga practice to reduce stress, anxiety and improve cognitive response and quality of life Pranayama yoga can be used as a nonpharmacological intervention to reduce postoperative pain. Other research has shown that deep breathing exercises (pranayama) could improve patients with long-term cardiovascular disease. Pranayama also improves the heart's electrical conditions, and thus reducing the incidence of ventricular repolarization dispersion in patients with arrhythmias (11). Another body-based method used to reduce pain and improve the patient's quality of life is Baduanjin sequential therapy (BST). BST is a physical exercise for patients in the rehabilitation stage and is popular in Chinese medicine. Patients who are given BST exercises will perform the intervention twice a day for 30 minutes each session for three days. The patients stand in a relaxed manner and perform abdominal breathing. BST helps improve the patients' quality of life as pain will reduce, oxygen saturation increases, and shortness of breath is reduced as well (12).

Another therapy that can be applied to Complementary and alternative therapy is Acupressure. Acupressure can be performed on patients who experience anxiety. The effect of acupressure is that it can cause a warm feeling, the pressure at a certain point can cause a feeling of comfort. kupressur done for 10 minutes per hand on the right hand and then the left hand. Pressure is applied to the Nei Guan (P6 or Inner Gate) point on the inner side (stomach) of the forearm. The first pressure is applied 
two and a half finger widths from the crease of the wrist. The pressure is applied about 2 inches lower towards the elbow (the point located between the two tendons). Point P6 can then be stimulated on both hands by applying firm pressure to the point using the index finger for one minute, while breathing shallowly through the nose(9).

\section{Mind Terapies}

This review indicates that the mind therapy which can be applied to reduce pain and anxiety is meditation. Meditation in this review refers to mindfulness and Islamic spiritual intervention. In this context, CAT therapy is not only provided for patients with heart disease but also those with chronic diseases such as cancer, by focusing on the mind (mind therapies). Patients who have chronic diseases such as cancer often experience psychological problems and physiological distress that affect their quality of life; thus, cancer patients can adopt a diet of healthy or herbal products that are consumable (13). This result is also in line with other studies, showing that patients with chronic diseases, such as breast cancer, can be given herbal therapy and spiritual healing. Spiritual healing is part of CAT that focuses on spirituality (14). This therapy concurs with the results of the analysis in this review, namely, patients who are undergoing post-cardiac surgery care, i.e., CABG, often experience problems related to psychological and physiological aspects. This review shows that Islamic spiritual healing can help reduce anxiety and become a positive coping in patients with chronic diseases(15). The spiritual therapy in this review is focused on mindfulness-based stress reduction (MBSR). MBSR is a combination therapy of breathing exercises, mindfulness meditation, and yoga with gentle movements. Providing MBSR for patients with chronic problems, such as heart disease, aims to reduce symptoms of depression, anxiety, stress. In addition, MBSR also increases blood pressure, boosts the immune system, and activates the nervous system (3). MBSR has a positive impact on reducing the risk of cardiovascular disease (16). In line with other studies on patients with $\mathrm{CABG}$, it is shown that spirituality and religious activities can reduce psychological problems, such as depression, anxiety, and stress in patients (17). Religious activities play a vital role in the patients' healing process and reduce mental disorders and cardiovascular problems $(18,19)$. 


\section{Sensory Therapies}

This literature review describes the aromatherapy and music therapy that can be used to reduce pain and anxiety in patients with heart disease. Some essential oils for aromatherapy that can be given to patients include rose, lemon, and peppermint. Research shows that aromatherapy reduces pain and anxiety due to catheter insertion (20). Essential oils and aromatherapy affect signal transmission to the olfactory nerves to release serotonin, endorphins, and noradrenaline; the presence of these hormones can reduce pain and anxiety (6). Essential oils or aromatherapy can be given to patients for 20 minutes using an oxygen mask, such as for those patients after undergoing CABG surgery. Research shows that patients who are given rose aromatherapy have less anxiety and feel more relaxed(21). Rose aromatherapy can reduce anxiety and increase relaxation, which affects the nervous and limbic systems so that the activity of the sympathetic nervous system is reduced (22). The central nervous system and GABA receptors, such as benzodiazepines, provide sedative and anti-anxiety effects (23).

Aromatherapy has healing benefits and is effective for pain management; it also affects essential body systems in the pain management process (24). Some aromatherapies are evident to lower blood pressure, anxiety, pulse rate, T-waves, and changes in blood pressure (25). Research shows that the administration of lemon aromatherapy to patients with acute myocardial infarction (AMI) had an effect on decreasing blood pressure on the third and fourth days. The study also reported that anxiety and pain in these patients were reduced. Besides, lemon aromatherapy has a neuroprotective effect by changing the ECG value to prevent arrhythmias. Lemon aromatherapy is also antispasmal (25).

Music therapy is part of sensory therapies. This literature review describes that patients who are given music therapy have a decreased score of pain and anxiety after CABG surgery. Music is a form of CAT that has been known for hundreds of years ago. Music is evident to function as therapy after some research evidence exists. Music is generally listened to using cellphones or music speakers. This review shows that music therapy can reduce neuropathic pain, cancer pain, palliative pain and postoperative pain. Music therapy that is provided for patients for 30 minutes can have a positive impact, namely accelerating the patient's healing process; music therapy also reduces pain and increases emotional dimension to reduce anxiety in patients (26). 
Research has shown that music therapy has a positive impact on pain experiences, reduces pain levels, reduces muscle tension, and reduces opioid use. Other pain that can be treated with music therapy is neuropathic pain, cancer pain, pain associated with debridement of burns, procedural. Patients who are given music therapy in several intensive units such as the ICU, palliative care areas and after surgery feel less pain and feel more relaxed. Other studies have shown that environmental modification and patient involvement, namely by means of the patient choosing music according to his choice, will show a more significant decrease in pain scores, besides environmental modifications such as dimming lights, providing blankets, turning off electronics and cellphones, can improve overall comfort.

\section{Conclusion}

Patients' experiences with psychological and physiological problems should be observed from a holistic point of view. Nurses' knowledge regarding CAT as a nursing intervention can improve the patients' conditions. CAT therapy is easy to implement in patients with acute or chronic diseases such as heart disease; it is very affordable and does not cause serious side effects. In addition to the benefits for patients, CAT also provides positive benefits for nursing institutions to integrate CAT materials into the educational curriculum so that prospective nurses can have adequate knowledge related to complementary therapies that can be applied to patients.

Complementary and alternative therapy has been carried out in several developed countries, in Indonesia, Holistic Nursing is a part of CAT, an association which has been formed called the Indonesian Holistic Nurses Association (HPHI). Holistic nursing contains patient care that focuses on bio-psycho-socio-spiritualcultural based on the nursing body of knowledge, namely Caring Watson's theory, Roger's energy theory and Integrative Nursing Theory. Services in holistic nursing include 1) mind body intervention: hypnotherapy, meditation relaxation, yoga, music therapy, etc ; 2) energy teraii: accupressure, reiki, healing touch magnet therapy; 3) other herbs and herbs, beauty, acupuncture, message, reflection, shiatsu, aromatherapy, etc. Holistic nursing in nursing services is very necessary given the importance of nursing services that focus on humans who are seen as unique. Caring Watson's theory explains that it reveals that there are ten carative factors that can reflect the caring behavior of a nurse. These ten factors are forming a humanisticaltruistic value system, instilling beliefs and expectations, developing sensitivity for 
oneself and others, fostering relationships of mutual trust and mutual help, increasing and accepting the expression of positive and negative feelings, using systematic problem-solving methods in taking decisions, improve interpersonal teaching and learning processes, provide an environment that supports, protects, and or improves mental, socio-cultural and spiritual, helps in the fulfillment of basic human needs, develops phenomenological existential power factors. This is consistent with nursing services on complementary and alternative therapy.

\section{REFERENCES}

1. RI PK. Hari Jantung Sedunia (World Heart Day): Your Heart is Our Heart Too. 2019.

2. Riskesdas K. Hasil Utama Riset Kesehata Dasar (RISKESDAS). J Phys A Math Theor [Internet]. 2018;44(8):1-200. Available from: http://arxiv.org/abs/1011.1669\%0Ahttp://dx.doi.org/10.1088/1751-

8113/44/8/085201\%0Ahttp://stacks.iop.org/1751-

$8121 / 44 / i=8 / a=085201$ ? ey=crossref.abc74c979a75846b3de48a5587bf708f

3. Nijjar PS, Connett JE, Lindquist R, Brown R, Burt M, Pergolski A, et al. Randomized Trial of Mindfulness-Based Stress Reduction in Cardiac Patients Eligible for Cardiac Rehabilitation. Sci Rep [Internet]. 2019;9(1):1-12. Available from: http://dx.doi.org/10.1038/s41598-019-54932-2

4. Chandrababu R, Kurup SB, Ravishankar N, Ramesh J. Effect of pranayama on anxiety and pain among patients undergoing cardiac surgery: A non-randomized controlled trial. Clin Epidemiol Glob Heal [Internet]. 2019;7(4):606-10. Available from: https://doi.org/10.1016/j.cegh.2019.01.009

5. Sayari S, Nobahar M, Ghorbani R. Effect of foot reflexology on chest pain and anxiety in patients with acute myocardial infarction: A double blind randomized clinical trial. Complement Ther Clin Pract [Internet]. 2021;42(December 2020):101296. Available from: https://doi.org/10.1016/j.ctcp.2020.101296

6. Hamlin AS, Robertson TM. Pain and Complementary Therapies. Crit Care Nurs Clin North Am [Internet]. 2017;29(4):449-60. Available from: https://doi.org/10.1016/j.cnc.2017.08.005

7. Delgado R, York A, Lee C, Crawford C, lii CB, Schoomaker E, et al. Assessing the Quality, Efficacy, and Effectiveness of the Current Evidence Base of Active Self-Care Complementary and Integrative Medicine Therapies for the 
Management of Chronic Pain : A Rapid Evidence Assessment of the Literature. 2014;9-20.

8. M. Torabi, M.Sc., M. Salavati A r. GS. Effect of Foot Reflexology Massage and Benson Relaxation Techniques on Anxiety and Physiological Indexes of Patients undergoing Coronary Heart Angiograp. Avicenna J Nurs Midwifery Care [Internet]. 2012;Volume 20(1). Available from: http://nmj.umsha.ac.ir/article-1-1108-en.html

9. Rahmani Vasokolaei Z, Rejeh N, Heravi-Karimooi M, Tadrisi SD, Saatchi K, Poshtchaman Z, et al. Comparison of the Effects of Hand Reflexology versus Acupressure on Anxiety and Vital Signs in Female Patients with Coronary Artery Diseases. Healthcare. 2019;7(1):26.

10. Martorella G, Graven L. Nurses ' Perception of a Tailored Web-Based Intervention for the Self-Management of Pain After Cardiac Surgery. 2018;4:114.

11. M.Ghunage BHPSG. Effect of Pranayama (Breathing Exercise) on Arrhythmias in the Human Heart - ScienceDirect. 2011.

12. Chen MG, Liang X, Kong L, Wang J, Wang F, Hu X, et al. Effect of Baduanjin Sequential Therapy on the Quality of Life and Cardiac Function in Patients with AMI after PCI: A Randomized Controlled Trial. Evidence-based Complement Altern Med. 2020;2020.

13. Alsharif $\mathrm{FH}$, Mazanec SR. The use of complementary and alternative medicine among women with breast cancer in Saudi Arabia. Appl Nurs Res [Internet]. 2021;48(November 2018):75-80. Available from: https://doi.org/10.1016/j.apnr.2019.05.019

14. Nayeri ND, Bakhshi F, Khosravi A, Najafi Z. The effect of complementary and alternative medicines on quality of life in patients with breast cancer: $A$ systematic review. Indian J Palliat Care. 2020;26(1):95-104.

15. Amjadian M, Bahrami Ehsan H, Saboni K, Vahedi S, Rostami R, Roshani D. A pilot randomized controlled trial to assess the effect of Islamic spiritual intervention and of breathing technique with heart rate variability feedback on anxiety, depression and psycho-physiologic coherence in patients after coronary artery bypass sur. Ann Gen Psychiatry [Internet]. 2020;19(1):1-11. Available from: https://doi.org/10.1186/s12991-020-00296-1

16. Levine GN, Lange RA, Bairey-merz CN, Davidson RJ, Jamerson K, Mehta PK, 
et al. Meditation and Cardiovascular Risk Reduction. 2017;

17. Lehrer P, Vaschillo B, Zucker T, Graves J, Katsamanis M, Aviles M, et al. Protocol for Heart Rate Variability Biofeedback Training. 2013;(September).

18. Ai EGN\& AL. Religion and the Use of Complementary and Alternative Medicine (CAM) Among Cardiac Patients. J Relig Helath. 2013;53:864-77.

19. Lucchese FA, Koenig HG. Religion, spirituality and cardiovascular disease : research , clinical implications , and opportunities in Brazil. 2013;28(1):103-28.

20. Akbari F, Rezaei M, Khatony A. Effect of peppermint essence on the pain and anxiety caused by intravenous catheterization in cardiac patients: A randomized controlled trial. J Pain Res. 2019;12:2933-9.

21. Fazlollahpour-Rokni F, Shorofi SA, Mousavinasab N, Ghafari R, Esmaeili R. The effect of inhalation aromatherapy with rose essential oil on the anxiety of patients undergoing coronary artery bypass graft surgery. Complement Ther Clin Pract. 2019;34(September 2018):201-7.

22. Miho Igarashi, Chorong Song, Harumi Ikei, Tatsuro Ohira and YM. Effect of Olfactory Stimulation by Fresh Rose Flowers on Autonomic Nervous Activity _ The Journal of Alternative and Complementary Medicine. J Altern Complement Med [Internet]. 2014;20. Available from: https://www.liebertpub.com/doi/pdf/10.1089/acm.2014.0029

23. Lee MS, Lee HW, Khalil M, Lim HS. Aromatherapy for Managing Pain in Primary Dysmenorrhea: A Systematic Review of Randomized Placebo-Controlled Trials. :1-14.

24. Melissa E Allard JK. Using Essential Oils to Enhance Nursing Practice and for Self-Care - PubMed. AM J nurs. 2016;

25. Rambod M, Rakhshan M, Tohidinik S, Nikoo MH. The effect of lemon inhalation aromatherapy on blood pressure, electrocardiogram changes, and anxiety in acute myocardial infarction patients: A clinical, multi-centered, assessor-blinded trial design. Complement Ther Clin Pract [Internet]. 2020;39(March):101155. Available from: https://doi.org/10.1016/j.ctcp.2020.101155

26. Dai WS, Huang ST, Xu N, Chen Q, Cao H. The effect of music therapy on pain, anxiety and depression in patients after coronary artery bypass grafting. $\mathrm{J}$ Cardiothorac Surg. 2020;15(1):1-5. 